\title{
Technical Note: Animal-borne CTD-Satellite Relay Data Loggers for real-time oceanographic data collection
}

\author{
L. Boehme ${ }^{1}$, P. Lovell ${ }^{1}$, M. Biuw ${ }^{1, *}$, F. Roquet ${ }^{2}$, J. Nicholson ${ }^{3}$, S. E. Thorpe ${ }^{4}$, M. P. Meredith ${ }^{4}$, and M. Fedak ${ }^{1}$ \\ ${ }^{1}$ NERC Sea Mammal Research Unit, Scottish Oceans Institute, University of St Andrews, St Andrews, KY16 8LB, UK \\ ${ }^{2}$ LOCEAN/Museum National d'Histoire Naturelle, France \\ ${ }^{3}$ Valeport Ltd., Totnes, UK \\ ${ }^{4}$ British Antarctic Survey, Natural Environment Research Council, High Cross, Madingley Road, Cambridge, CB3 0ET, UK \\ * now at: Norwegian Polar Institute, Polar Environmental Centre, 9296 Troms $\emptyset$, Norway
}

Received: 29 May 2009 - Published in Ocean Sci. Discuss.: 30 June 2009

Revised: 30 November 2009 - Accepted: 4 December 2009 - Published: 15 December 2009

\begin{abstract}
The increasing need for continuous monitoring of the world oceans has stimulated the development of a range of autonomous sampling platforms. One novel addition to these approaches is a small, relatively inexpensive datarelaying device that can be deployed on marine mammals to provide vertical oceanographic profiles throughout the upper $2000 \mathrm{~m}$ of the water column. When an animal dives, the CTD-Satellite Relay Data Logger (CTD-SRDL) records vertical profiles of temperature, conductivity and pressure. Data are compressed once the animal returns to the surface where it is located by, and relays data to, the Argos satellite system. The technical challenges met in the design of the CTD-SRDL are the maximising of energy efficiency and minimising size, whilst simultaneously maintaining the reliability of an instrument that cannot be recovered and is required to survive its lifetime attached to a marine mammal. The CTD-SRDLs record temperature and salinity with an accuracy of better than $0.005^{\circ} \mathrm{C}$ and 0.02 respectively. However, due to the limited availability of reference data, real-time data from remote places are often associated with slightly higher errors. The potential to collect large numbers of profiles cost-effectively makes data collection using CTD-SRDL technology particularly beneficial in regions where traditional oceanographic measurements are scarce or even absent. Depending on the CTD-SRDL configuration, it is possible to sample and transmit hydrographic profiles on a daily basis, providing valuable and often unique information for a real-time ocean observing system.
\end{abstract}

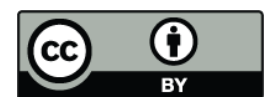

Correspondence to: L. Boehme (lb284@st-andrews.ac.uk)

\section{Introduction}

One of the greatest impediments to our understanding of ocean processes is a lack of in situ data from remote regions. As a consequence, there is currently a lack of ability to detect and monitor changes in oceanographic conditions in some regions known to be important climatically, and a shortage of data with which to challenge and validate climate models. Understanding the ocean's role in the climate system requires sustained sampling of the time-varying oceanic storage of heat and freshwater (Roemmich et al., 2004; Quadfasel, 2005). While the former reveals how the ocean absorbs and redistributes heat from the atmosphere, the latter reflects variability in precipitation and evaporation through salinity anomalies, with the added complexity of anomalies due to sea ice and glacial ice-related processes in the polar regions.

The Global Ocean Observing System (GOOS) is designed to fulfil these requirements (Alverson, 2008a), and necessitated the creation of special profiling floats with which to observe the temperature and salinity of the world's oceans down to $2000 \mathrm{~m}$ depth. The broad-scale near global array of profiling floats, known as Argo, has already grown to be a major component of GOOS. Deployments began in 2000 and, by the second half of 2007, 3000 floats were distributed over the global oceans. This array is providing about 100000 hydrographic profiles and velocity measurements per year (Gould et al., 2004). The Argo array is designed for broad-scale ocean sampling at spatial intervals of hundreds of kilometres, greater than the size of eddies and boundary currents (Roemmich et al., 2004). Although the profiling float has enormous potential for these broad-scale ocean observations, it does not provide a complete observational strategy (Alverson, 2008b). Argo is designed to sample the oceans between

Published by Copernicus Publications on behalf of the European Geosciences Union. 
$60^{\circ} \mathrm{N}$ and $60^{\circ} \mathrm{S}$ and the profiling floats lack the capability to deliver real-time data from below the sea-ice zones in the polar regions. So it is essential that parallel advances are made in the measurement of air-sea exchanges and smallscale sampling for estimation of lateral fluxes. It is necessary to sample at higher spatial resolution in a "line-sampling" mode (i.e. section-based data distribution), resolving eddies and boundary currents for flux calculations, and to sample from ocean boundary to ocean boundary for flux integration. Research vessels lend themselves to the line-sampling mode, as reflected in the data collection strategies and ocean heat/freshwater transport estimates from the World Ocean Circulation Experiment and other comparable programmes (e.g. Ganachaud and Wunsch, 2000).

In this paper, we discuss and present recent advances in a novel technique that complements well the existing observing systems. Autonomous CTD-Satellite Relay Data Loggers (CTD-SRDLs) can be attached to marine animals, and report vertical profiles of conductivity, temperature and pressure to a maximum depth of around $2000 \mathrm{~m}$ (depending on species). The implementation of this technique has great potential to help populate remote and previously data-sparse regions (Fedak, 2004). Whilst the underlying concept is not new (Evans, 1970; Boehlert et al., 2001), CTD-SRDLs are the first animal-borne instruments that record full temperature and conductivity profiles, and enable transmission of these data in near real-time. This latter functionality is a key requirement for a fully-enabled ocean observing system, while the ability to return salinity data (derived from temperature, conductivity and pressure) is especially important in regions where the water column structure is dominated by salinity changes, e.g. the polar and subpolar oceans. The information returned from CTD-SRDLs is relevant not only to the study of physical structures of the oceans (Lydersen et al., 2002; Boehme et al., 2008a,b; Costa et al., 2008; Charrassin et al., 2008; Roquet et al., 2009; Meredith et al., 2009), but can also be useful for studying the ecology of the carrying animals (Lydersen et al., 2002; Hooker and Boyd, 2003; Lydersen et al., 2004; Charrassin et al., 2004; Biuw et al., 2007).

While the measurements returned by CTD-SRDLs are neither regular in terms of spatial and temporal coverage (compared, for example, to satellite measurements of oceanographic fields), these studies provide valuable in situ information about the subsurface structure of the ocean. The use of oceanic predators for remote data collection, although suffering from the inability to predetermine the locations of sample collection, can benefit from the ability of such predators to select foraging areas. Sampling is not uniform, but in many cases the predators act as "adaptive samplers" by targeting foraging areas, which are likely to coincide with many of the regions of most interest to biological and physical oceanographers (Guinet et al., 2001; Boehme et al., 2008b). This high resolution sampling across areas of strong gradients will help minimise spatial aliasing. Furthermore, migrations to and from these focal foraging areas are often

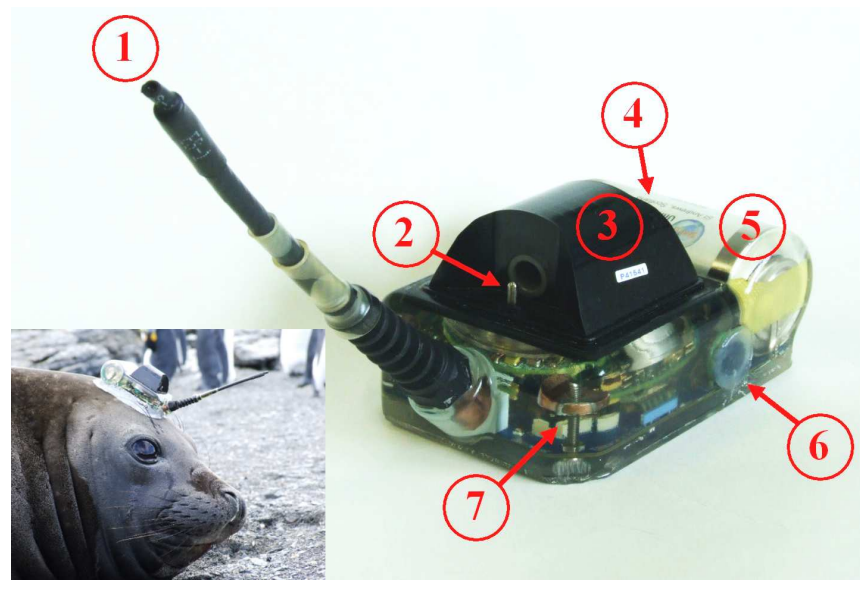

Fig. 1. Picture of a CTD-Satellite Relay Data Logger (CTD-SRDL) with antenna (1), temperature probe (2), inductive cell (3), pressure sensor (not visible) (4), battery (5), communications port (6) and wet-dry sensor (7). Insert: CTD-SRDL deployed on a southern elephant seal.

highly directed, and regularly cross major ocean fronts, providing a combination of transect-type and mooring-like data (Boehme et al., 2008a,b; Costa et al., 2008; Meredith et al., 2009; Roquet et al., 2009). With careful selection of species, gender and age of the animals, as well as the geographic location and time of tagging, it is even possible to undertake focused, highly cost-effective oceanographic studies in regions that might be difficult, and therefore expensive to access in any other way (Nicholls et al., 2008).

\section{Design}

The series 9000 CTD-SRDL (Fig. 1) is designed and built at the NERC Sea Mammal Research Unit (SMRU), St Andrews, UK. It consists of a $401 \mathrm{MHz}$ RF unit and antenna for data transfer via the Argos system (Argos, 1996), a lithiumthionyl chloride $\left(\mathrm{Li}-\mathrm{SOCl}_{2}\right) \mathrm{D}$-cell battery $\left(\mathrm{LSH} 20^{1}\right)$ and a Hitachi H8/3048 microprocessor programmed to act as the data logger, data compression tool and to schedule data transfer. The CTD sensor package is built and calibrated at Valeport Ltd. ${ }^{2}$, Devon, UK. Data from various sensors are collected when pre-programmed conditions of time and depth are met. Sampling algorithms onboard the CTD-SRDL detect the deepest point of a dive, and then begin rapidly sampling temperature, conductivity and pressure until the surface is reached. The limited Argos rate of data transfer and energy constraints (see Sect. 5) do not allow all data points to be transmitted. Therefore, a sub-set of pressure points with corresponding temperatures and conductivities are selected for transmission from these high-resolution data (see Sect. 4).

\footnotetext{
${ }^{1}$ http://www.saftbatteries.com

${ }^{2}$ http://www.valeport.co.uk/
} 
Detailed data from the pressure sensor and information from a wet-dry sensor are collected and used to form detailed individual dive and haul-out records along with synoptic summary records of animal behaviour (Fedak et al., 2002). Data are then stored in internal memory and transmitted at the surface via the Argos satellite system (Argos, 1996).

Potential effects on an animal's normal behaviour must be considered whenever an animal-borne instrument is designed. While the "rule of thumb" for complete instruments dictates that they weigh no more than $2-5 \%$ of the animal's total body weight (Cochran, 1980), subsequent studies have shown the importance of species-specific considerations. Aldrige and Brigham (1988) showed that adverse impacts from the weight of instruments should be examined not only for each species but also for size variations within each species if no such data from closely related species exist. The CTD-SRDL is designed to minimise any effects on an animal, i.e. shaped to minimise hydrodynamic drag. The outside dimensions are $12.0 \mathrm{~cm}$ length, $7.2 \mathrm{~cm}$ width and $6.0 \mathrm{~cm}$ height (Fig. 1). The antenna length is $15 \mathrm{~cm}$. The volume is about $254 \mathrm{~cm}^{3}$ with a mass of $545 \pm 5 \mathrm{~g}$ in air and $255 \pm 5 \mathrm{~g}$ in sea water. The cross-sectional area is about $35 \mathrm{~cm}^{2}$. Referring to the "rule of thumb" for the animal's total body weight, an instrumented animal should therefore have a minimum mass of $25 \mathrm{~kg}$. CTD-SRDLs have been deployed on harbour, grey, hooded, harp, ringed, Weddell, crabeater, northern and southern elephant seals, and also on California sea lions, and leatherback turtles, which are all substantially larger than the minimum required size. Due to animal behaviour, CTDSRDLs must sometimes be attached to the head of an animal to increase the surface time sufficiently to make a transmission possible. In this case, the weight of the CTD-SRDL is of greater importance, because the head often needs to be accelerated in order to catch prey. Previous practical experience with CTD-SRDLs and data loggers of similar size and weight has showed no detectable harm on a variety of animals (McMahon et al., 2008). Analyses on adult female southern elephant seals $(250-800 \mathrm{~kg})$ on Macquarie Island showed no measurable effect. For instance, females carrying tags gained the same weight over winter (and summer) as those not carrying tags (Hindell, personal communication, 2008).

\section{Oceanographic sensors}

The design requirements for a CTD sensor to be integrated into a small animal-borne instrument are particularly demanding. It has to use almost no power (about $1.5 \mathrm{~mA}$, see Sect. 5), be virtually indestructible, and yet be minimised in size and weight. A key issue was thus to determine the required accuracy of the oceanographic sensors to be useful for oceanography, and to incorporate these requirements into the design specifications. Recent studies show that mid-depth Southern Ocean temperatures have warmed by as much as $0.17^{\circ} \mathrm{C}$ since the 1950 s (Gille, 2002), but long-term changes in the deep ocean temperature are usually of the order of $0.01{ }^{\circ} \mathrm{C}$ per decade (Zenk et al., 2003; Fukasawa et al., 2004). Recent examinations of surface and near-surface salinity changes showed that long-term changes of salinity were of the order of 0.02 per decade (Curry et al., 2003; Boyer et al., 2005). The salinity changes at greater depths are somewhat smaller in the order of $0.005-0.01$ per decade (Meredith et al., 2008). To detect such small changes in the deep ocean, high accuracy measurements are necessary. Ship-based CTDs are traditionally used, but also Argo floats generally achieve these accuracies (Wong et al., 2003; Boehme and Send, 2005; Wong and Owens, 2009). Upper ocean changes are easier to detect (as shown above). Expendable bathythermographs (XBTs), which are traditionally used to provide very large numbers of in situ ocean temperature profiles have an accuracy of \pm 0.02 to $\pm 0.1^{\circ} \mathrm{C}$ (Boyd and Linzell, 1993; Lockheed Martin Sippican, Inc., 2009). Expendable CTDs (XCTDs) also record salinity with an accuracy of about 0.06 (Lockheed Martin Sippican, Inc., 2009), which is not accurate enough to detect the above-mentioned long-term changes in the upper ocean, but is sufficient to position strong gradients found at boundaries of eddies or across ocean fronts. Remote sensing plays an important part, when large areas need to be covered, e.g. sea surface temperature (SST) is routinely measured by satellite with an accuracy of 0.1 to $0.5^{\circ} \mathrm{C}$ and a spatial resolution between 1 and $50 \mathrm{~km}$ (McClain et al., 1985; Reynolds et al., 2005). This might be sufficient to detect long term changes at the surface, but will not reveal any information about the subsurface. Accordingly, in line with the magnitude of signals being measured and the capabilities of other complementary techniques, there is a requirement for CTD-SRDLs to provide data with proven accuracies of $\pm 0.01{ }^{\circ} \mathrm{C}$ for temperature and \pm 0.02 for salinity to detect long-term changes in the upper to mid-depth ocean. While these sensor accuracies in themselves are quite easily achievable, they are substantially harder to attain in genuine deployments due to other requirements and the nature of the deployment.

The pressure sensor is incorporated in the CTD package of the CTD-SRDL (Fig. 1). This sensor consists of a Keller series-PA7 piezoresistive pressure transducer ${ }^{3}$ (Keller $\mathrm{AG}, \mathrm{CH}$ ) with a diameter of $15 \mathrm{~mm}$. A high-sensitivity piezoresistive silicon chip is used for pressure sensing. The chip is protected from ambient influences by a stainless steel $(316 \mathrm{~L})$ housing sealed with a concentrically corrugated diaphragm. The housing is filled with silicone oil for the transfer of the pressure from the diaphragm to the sensing component. The fully welded housing is vacuumtight. The pressure range given by the manufacturer is up to $2000 \mathrm{dbar}$ with an accuracy of better than $1 \%$ of the full-scale reading and comparisons with a SeaBird Electronics (SBE) 911plus CTD showed an accuracy of better than $0.25 \%$ of

\footnotetext{
${ }^{3}$ http://www.keller-druck.ch/picts/pdf/engl/7e.pdf
} 
Table 1. Summary of calibration checks done by Valeport Ltd., Devon, UK. 10 CTD-SRDLs were calibrated and then re-tested against one known temperature and salinity and against a range of pressures from $0 \mathrm{dbar}$ to $2000 \mathrm{dbar}$ in December 2007.

\begin{tabular}{rccc}
\hline SRDL ID & $\begin{array}{c}\text { Maximum deviation in } \\
\text { temperature }[\mathrm{mK}]\end{array}$ & $\begin{array}{c}\text { Maximum deviation in } \\
\text { conductivity }\left[10^{-3} \mathrm{mS} / \mathrm{cm}\right]\end{array}$ & $\begin{array}{c}\text { Maximum deviation in } \\
\text { pressure [dbar] }\end{array}$ \\
\hline 10857 & 0 & 4 & 0.214 \\
10859 & 2 & 1 & 0.180 \\
10851 & 3 & 6 & 0.616 \\
10854 & 2 & 3 & 0.861 \\
10849 & 1 & 9 & 0.415 \\
10847 & 2 & 2 & 0.491 \\
10853 & 1 & 8 & 0.071 \\
10850 & 2 & 9 & 0.575 \\
10861 & 3 & 5 & 0.405 \\
10848 & 2 & 2 & 0.612 \\
Mean & 1.800 & 4.900 & 0.444 \\
Std & 0.919 & 2.998 & 0.239 \\
Max & 3.000 & 9.000 & 0.861 \\
\hline
\end{tabular}

the actual reading (SMRU/BAS, unpublished data), i.e. better than $5 \mathrm{dbar}$ at the full scale reading, while checks in the calibration lab at Valeport Ltd showed errors in the pressure reading of less than 1 dbar over the full range (Table 1). The temperature sensitivity of the pressure transducer is below $1 \mathrm{dbar}$ over the expected temperature range. So far, no change in linearity of the pressure sensor has been observed over time. To avoid negative pressure offsets to be recorded at the surface, which would increase the necessary bits to describe such values and to account for any possible long-term drifts, pressure readings are also taken whenever the wet-dry sensor detects the surface, and if an offset exists, pressure is reset to zero.

The CTD package is equipped with a Platinum Resistance Temperature Detector (PRT). The PRT works on the principle of resistance through a fine platinum wire as a function of temperature, e.g. the most common type (PT100) has a resistance of $100 \mathrm{ohms}$ at $0^{\circ} \mathrm{C}$ and $138.4 \mathrm{ohms}$ at $100^{\circ} \mathrm{C}$. The probe is housed in a metal tube in front of the conductivity sensor (Fig. 1). Valeport Ltd. states an accuracy (standard devation) of better than $\pm 0.005^{\circ} \mathrm{C}$. This was confirmed by post calibration checks done by Valeport Ltd. (Table 1) and by recalibrations at the calibration lab at the Naval Postgraduate School in Monterey, CA, USA, which also showed that the temperature readings deviate on average by less than $\pm 0.002{ }^{\circ} \mathrm{C}$ to a known reference (Fig. 2).

An inductive method was selected over an electrode cell to measure the conductivity of the seawater. A non pumped electrode cell would probably also produce acceptable performance and they tend not to be affected as much as inductive cells by the immediate environment. However, we could not find a small, stable and robust electrode based cell with low power consumption, which would fit into the existing SRDL. Valeport Ltd. developed an inductive cell with

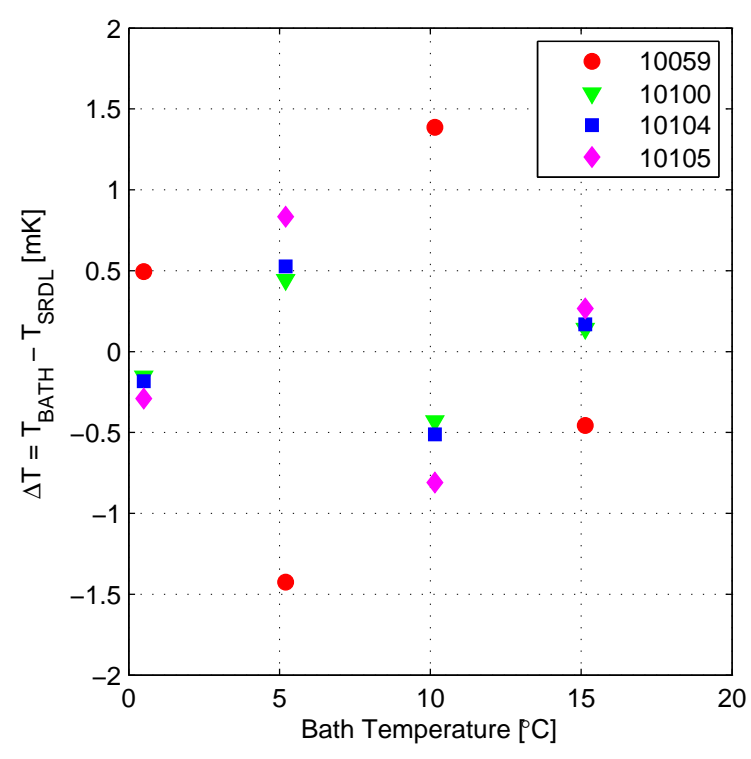

Fig. 2. Temperature differences between four controlled temperature baths and measurements from four CTD-SRDLs (colourcoded).

titanium and ceramic construction, which gives improved durability and reduces the risk of sensor drift due to corrosion. Valeport Ltd. also developed a new digital measurement technique for the inductive sensor, resulting in a highly accurate sensor with much lower power consumption than traditional methods, and with much shorter sampling duration. One known feature of some inductive cells is that they compress slightly under pressure. This could result in a significant effect on the necessarily small bore of the inductive 
Tag 10174

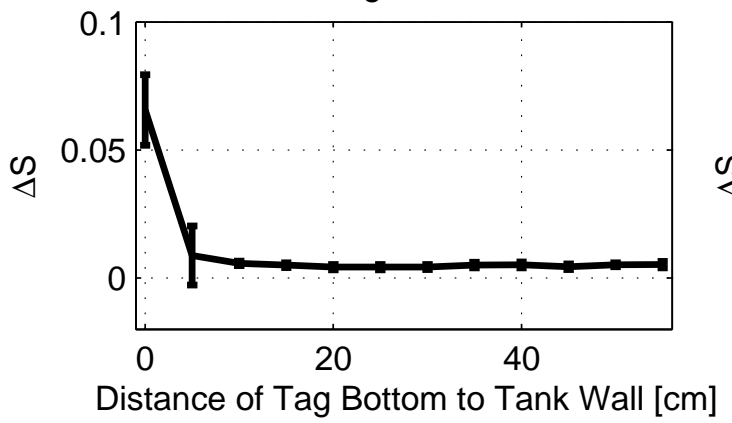

Tag 10108

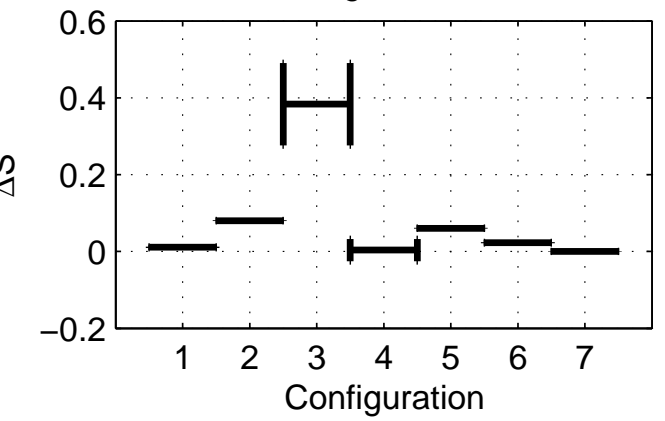

Fig. 3. External field effect on salinity. Left: Differences and their standard deviation between the bath salinity and CTD-SRDL data. A CTD-SRDL was moved towards a wall of the calibration tank. The bottom of the CTD-SRDL was facing the wall. Right: The deviation between the CTD-SRDL salinity and the calibration tank salinity including standard deviation using different deployment configurations: bottom at wall (1), side at wall (2), conductivity cell at wall (3), random movement (4), different cable tie configurations (5 and 6 ), no movements in the middle of the tank (7).

cell on the CTD-SRDL. An inaccuracy of about $1 \mu \mathrm{m}$ in the bore would push the sensor out of specification. Again, the use of high strength ceramics in the construction mean that even at $2000 \mathrm{dbar}$ pressure, the conductivity cell retains its shape sufficiently. Valeport Ltd. calibrates the conductivity sensor to an accuracy better than $\pm 0.01 \mathrm{mS} / \mathrm{cm}$. Postcalibration checks at Valeport Ltd. show that the average of the worst case deviations within the calibration curve is $0.005 \mathrm{mS} / \mathrm{cm}$ (Table 1). This would lead to an error in the derived salinity of \pm 0.02 for the claimed accuracies and \pm 0.01 with the measured deviations. These tests show that the accuracies of the temperature and the derived salinity before deployment in an undisturbed environment are better than the set requirements.

One disadvantage of a single bore inductive cell is the increased risk of interference of the external field of the sensor. During calibration tank experiments, we tested the CTDSRDLs in different configurations to estimate possible effects on the salinity measurements (Fig. 3). During the first test, the CTD-SRDL was moved towards the calibration tank wall (non-conductive), with the bottom of the CTD-SRDL facing the wall. As the distance between the tank wall and the bottom of the CTD-SRDL was reduced, an effect on the derived salinity values became obvious at a distance shorter than $10 \mathrm{~cm}$ (Fig. 3). When the bottom of the CTD-SRDL was in contact with the tank wall, the salinity values were up to 0.075 too low. The CTD-SRDL was also turned in the tank, e.g. with the side of the instrument in contact with the wall. The effect on salinity was greatest when the inductive cell was in direct contact with the interference, with the resulting deviations in salinity being up to 0.5 (Fig. 3). Interestingly, a second salinity test with the bottom of the CTD-SRDL touching the tank wall gave deviations of around 0.01, much less than in the first test (Fig. 3). This, and the high magnitude of the deviations, suggests that the conductivity sensor is highly sensitive to obstructions in the external field.
During deployment, CTD-SDRLs are sometimes attached to a plate with cable ties, with the plate already having been attached to the animal's fur. These configurations were also tested in the calibration tank experiments. Cable ties were placed around the CTD-SRDL in front and behind the conductive cell. These cable ties were seen to have a distinct effect on the conductivity reading (offset of order 0.05, Fig. 3) and hence should be avoided, or alternatively the data will need to be corrected before use. However, these calibration tests also suggest that even if no cable ties and/or plates are used, the proximity of the conductivity cell to the body or head of the animal, containing several tissues with different conductive or insulating properties, is likely to have an effect on the conductivity measurements. The salinity data will therefore have to be corrected accordingly.

\section{Data compression and transmission}

Animals and marine mammals in particular present one of the most demanding challenges for telemetry systems. Marine mammals spend most of their time under water and often range over global distances. There are many ways to broadcast data from marine mammals (Fedak et al., 2002), but animals need to be at the surface for most of them. Time at the surface is often limited to a couple of minutes minimising the possibilities for any telemetry system to transmit data. In addition, it is only possible to relay global, near realtime data from free ranging animals by utilising satellite systems. Many different satellite systems are available for animal and oceanographic telemetry (e.g. Argos, 1996; Iridium, 2003; Globalstar, 2009), but none were designed exclusively for this purpose. The Argos system (Argos, 1996) has been the most successfully used for global animal and oceanographic telemetry not only allowing data transfer, but also delivering estimates of the transmitters' location. Therefore, 
instruments using the Argos telemetry system do not have to carry additional sensors to determine their position, which in turn leads to a reduced size and energy consumption. These facts, its global coverage (including the polar regions), the simple data transfer protocol (no handshake required) and the long experience of the SMRU telemetry group using the Argos system led us to use it again for the CTD-SRDLs. However, recent developments in satellite communications might lead to other satellite systems to be integrated into the CTDSRDLs (see Sect. 8).

While animal telemetry is occupying a rapidly increasing fraction of Argos throughput, the system does have some drawbacks for telemetry from marine mammals. Transmitters that are certified to communicate with Argos must conform to very strict frequency tolerances. Individual messages (termed "uplinks") may be up to $960 \mathrm{~ms}$ in duration and it takes 4 or more complete uplinks for the system to compute a location and provide an estimated accuracy (Argos, 1996). This accuracy depends on the number of uplinks received, the temporal pattern of these receptions and the position of the satellite relative to the transmitter (Vincent et al., 2002). Uplinks may contain a maximum of 256 bits ( 32 bytes) per message in a rigid format and Argos sets a minimum interval of $40 \mathrm{~s}$ between transmissions (Argos, 1996). However, Argos effectively limits the usable number of bits to 228, because 28 bits are now used for the PTT (Platform Transmitter Terminal) number.

These restrictions, combined with the fact that animals are only briefly and infrequently at the surface (for example, $10 \%$ of the time for elephant seals), place unusually tight limits on the rate of data transfer. These and those limitations caused by energy constraints (see Sect. 5), demand complex data collection software and extreme data compression, which in turn demand a sophisticated data collection platform. This data transfer restriction is compounded by the fact that satellites are not always visible. However, the data transmission restrictions resulting from energy constraints and Argos restrictions do not interact in an additive way and steps taken to circumvent Argos limitations also serve to help avoid energy constraints. Detailed descriptions of the collection and compression of behavioural data are given by Fedak et al. (2002); here, we concentrate on the hydrographic data compression. The design of the compression method of the CTD data is determined by the user and can be changed at any time before the deployment. Therefore, we describe the standard program that is used in most cases and is the default setup appropriate for general application.

The CTD-SRDL samples pressure every $4 \mathrm{~s}$ during a dive. At this point only the pressure sensor of the CTD package is utilised to minimise energy consumption. The deepest point of a dive is detected by analysing the trend provided by the pressure sensor. One day is divided into four 6-hours periods in which one full CTD profile is recorded and if this deepest depth exceeds a pre-set value in a 6 -h period, the CTD-SRDL switches to "sampling-mode". This setting is chosen to en- sure that the batteries last long enough to perform 4 CTD profiles a day, assuming a 12 month deployment with an average diving depth of $1000 \mathrm{~m}$. On the ascent, the CTD-SRDL then begins sampling temperature, conductivity and pressure at $1 \mathrm{~Hz}$ until the surface is reached. From this full profile data, salinity is calculated. In doing so, a 1-s time lag (derived empirically) is applied to the conductivity readings to account for the different time constants between the temperature and conductivity sensors. While the conductivity time constant is instantaneous, the temperature sensors are afflicted with a time constant of about one second. Then, a 5-s median filter is applied to the temperature and salinity time series of that particular profile to remove any spikes, instead of a mean filter, which could introduce a bias. This 5 -s median filter depends on any spikes to be shorter than two seconds (affecting two readings), but a longer filter would flatten the profile too much.

Finally, a set of four 256 bit Argos messages is produced. One message contains a detailed dive summary. Another message comprises information about the cruise/haul-out pattern in the 6-h period (see Fedak et al., 2002, for more details), while the CTD data are compressed into two other messages. Only 17 representative depth points with corresponding temperature and salinity values are selected for transmission using a combination of 8 predefined depths, 7 inflection points, which are chosen via a broken-stick point selection algorithm (Fedak et al., 2002) and the extreme depths. The first message contains 8 fixed depth T/S pairs and the shallowest measurements. The second message contains 7 broken-stick and the deepest triplets. The fixed depth points are chosen according to the deepest point of the dive based on Table 2. The remaining seven points are selected between the fixed depth points based on the broken-stick method.

The standard software has a temperature range from $-2{ }^{\circ} \mathrm{C}$ to $30^{\circ} \mathrm{C}$ with a resolution of $0.10 \%$ of the temperature range of the specific profile, i.e. if the maximum and minimum temperatures within one profile are less than $10.24^{\circ} \mathrm{C}$ apart, then the resolution will be better than $0.01{ }^{\circ} \mathrm{C}$. Only the minimum and maximum temperatures are transmitted as full values while all intermediate values are associated to one of $10 \mathrm{bits}$, hence the resolution depends on the temperature range. This setup will thus produce a temperature resolution that will be better than the required accuracy in most of the high latitude oceans. The salinity range is 8.19 , typically between 29 and 37 to be applicable in most of the world oceans. The resolution of the transmitted data points is about $0.39 \%$ of the salinity range of that specific profile, i.e. if the salinity range within the profile is less than 2.56 , a resolution of better than 0.01 is achieved ( 8 bit resolution).

The compressed hydrographic and behavioural data are then transmitted during each surfacing of the animal. The CTD-SRDL antenna is oriented so as to be out of the water when the animal is at the surface (Fig. 1). The minimum interval between two successive messages has to be 
Table 2. Fixed depth points transmitted depending on dive depth. All points are transmitted within one Argos message, except the one in brackets, which will be sent together with the broken-stick depths.

\begin{tabular}{|c|c|c|c|c|c|c|c|c|c|c|}
\hline \multicolumn{5}{|l|}{ Pressure } & \multicolumn{6}{|c|}{ Fixed depths used } \\
\hline $10 \mathrm{dbar}$ & $X$ & $\mathrm{X}$ & $\mathrm{X}$ & $X$ & $X$ & $\mathrm{X}$ & $\mathrm{X}$ & $X$ & & \\
\hline $14 \mathrm{dbar}$ & $X$ & & & & & & & & & \\
\hline $20 \mathrm{dbar}$ & $\mathrm{X}$ & $\mathrm{X}$ & $\mathrm{X}$ & $\mathrm{X}$ & $\mathrm{X}$ & $\mathrm{X}$ & $\mathrm{X}$ & (X) & $(\mathrm{X})$ & \\
\hline $26 \mathrm{dbar}$ & $\mathrm{X}$ & & & & & & & & & \\
\hline $30 \mathrm{dbar}$ & $\mathrm{X}$ & $\mathrm{X}$ & $\mathrm{X}$ & $\mathrm{X}$ & $(\mathrm{X})$ & & & & & \\
\hline $36 \mathrm{dbar}$ & (X) & & & & & & & & & \\
\hline $40 \mathrm{dbar}$ & $\mathrm{X}$ & $\mathrm{X}$ & $\mathrm{X}$ & & & & & & & \\
\hline $50 \mathrm{dbar}$ & $X$ & $\mathrm{X}$ & $\mathrm{X}$ & $\mathrm{X}$ & $X$ & $\mathrm{X}$ & $\mathrm{X}$ & $\mathrm{X}$ & $X$ & $\mathrm{X}$ \\
\hline $60 \mathrm{dbar}$ & & $X$ & $(\mathrm{X})$ & & & & & & & \\
\hline $80 \mathrm{dbar}$ & & (X) & & (X) & & & & & & \\
\hline $100 \mathrm{dbar}$ & & $\mathrm{X}$ & $\mathrm{X}$ & $\mathrm{X}$ & $X$ & $X$ & $\mathrm{X}$ & $\mathrm{X}$ & $X$ & $\mathrm{X}$ \\
\hline $150 \mathrm{dbar}$ & & & $\mathrm{X}$ & $\mathrm{X}$ & $\mathrm{X}$ & $(\mathrm{X})$ & & & & \\
\hline $200 \mathrm{dbar}$ & & & & $X$ & $X$ & $\mathrm{X}$ & $\mathrm{X}$ & $\mathrm{X}$ & $\mathrm{X}$ & $\mathrm{X}$ \\
\hline $300 \mathrm{dbar}$ & & & & & $\mathrm{X}$ & $\mathrm{X}$ & $\mathrm{X}$ & $X$ & $\mathrm{X}$ & (X) \\
\hline $400 \mathrm{dbar}$ & & & & & & $X$ & $(\mathrm{X})$ & & & \\
\hline $500 \mathrm{dbar}$ & & & & & & & $\mathrm{X}$ & $\mathrm{X}$ & $X$ & $\mathrm{X}$ \\
\hline $750 \mathrm{dbar}$ & & & & & & & & $X$ & $\mathrm{X}$ & $\mathrm{X}$ \\
\hline $1000 \mathrm{dbar}$ & & & & & & & & & $\mathrm{X}$ & $\mathrm{X}$ \\
\hline $1500 \mathrm{dbar}$ & & & & & & & & & & $\mathrm{X}$ \\
\hline
\end{tabular}

$40 \mathrm{~s}$ (Argos, 1996). However, sometimes the CTD-SRDL is underwater, because of waves or the animal's movements, so that the next transmission would not be received by a satellite, or would be delayed. The average surfacing time of e.g. an elephant seal is around $130 \mathrm{~s}$, which would theoretically allow the CTD-SRDL to send 3 messages. Unfortunately, Argos satellites are not always available and the low power of the transmitter together with the small antenna result in messages not being received by the Argos satellite system. Due to its high compression, all bits in any one value are significant and errors during the receiving or decoding process have a great impact. Such "flipped bits" can result in wrong values or, more significantly, can change the e.g. temperature range of a profile and alter all temperature values. Therefore, a pseudo-random method to schedule the transmission of an unbiased sample of stored profiles is used and some messages are received more than once, allowing to check and correct "flipped bits". If, by chance, a CTD-SRDL is recovered at a later stage, all data collected for transmission, whether or not they were successfully relayed, can be downloaded. This data is compressed based on Table 2, but still in full resolution.

To quantify the impact of these transmission issues, data from more than 115000 messages returned from CTDSRDLs deployed on southern elephant seals during 2004 and 2005 were analysed (Fig. 4). For more than $75 \%$ of all surfacings, 2-3 messages were received (Fig. 4) resulting in about 2 CTD profiles on average per day. A third of this data might have only the seven or eight points of one message. The limited surface time also reduces the possibilities of a position fix by the Argos system, which requires at least 4 received messages (Argos, 1996). Only for less than $25 \%$ of all surfacings are four or more messages received and a position calculated (Fig. 4). Consequently, positions for some surfacings are determined using delayed mode auxiliary location processing, typically by removing locations requiring unrealistic swimming speeds for a given species. Further information on post-processing such data is given by Mcconnell et al. (1992) and Lonergan et al. (2009). The position of the CTD profile is then assumed to be between the framing surface positions, with the relative distances to each framing position determined by their relative times of occurrence. In general, the accuracy of the position for each CTD-SRDL profile is of the order of $2 \mathrm{~km}$. This is less accurate than the position information typically associated with e.g. ship-based CTD profiles, but is entirely adequate for general open-ocean studies. There is currently much effort by animal biologists and statisticians to improve these position estimates using a variety of movement models and state-space approaches. Furthermore, since 2008 Argos provides error ellipsis estimates (major and minor axis lengths and orientations relative to North/South) for each position fix, and these will also be re-calculated and provided in delayed-time for past deployments. This will substantially improve the location error estimates, and lead to movement models with smaller uncertainty for interpolated positions such as those calculated for CTD profiles for the delayed-mode data. 

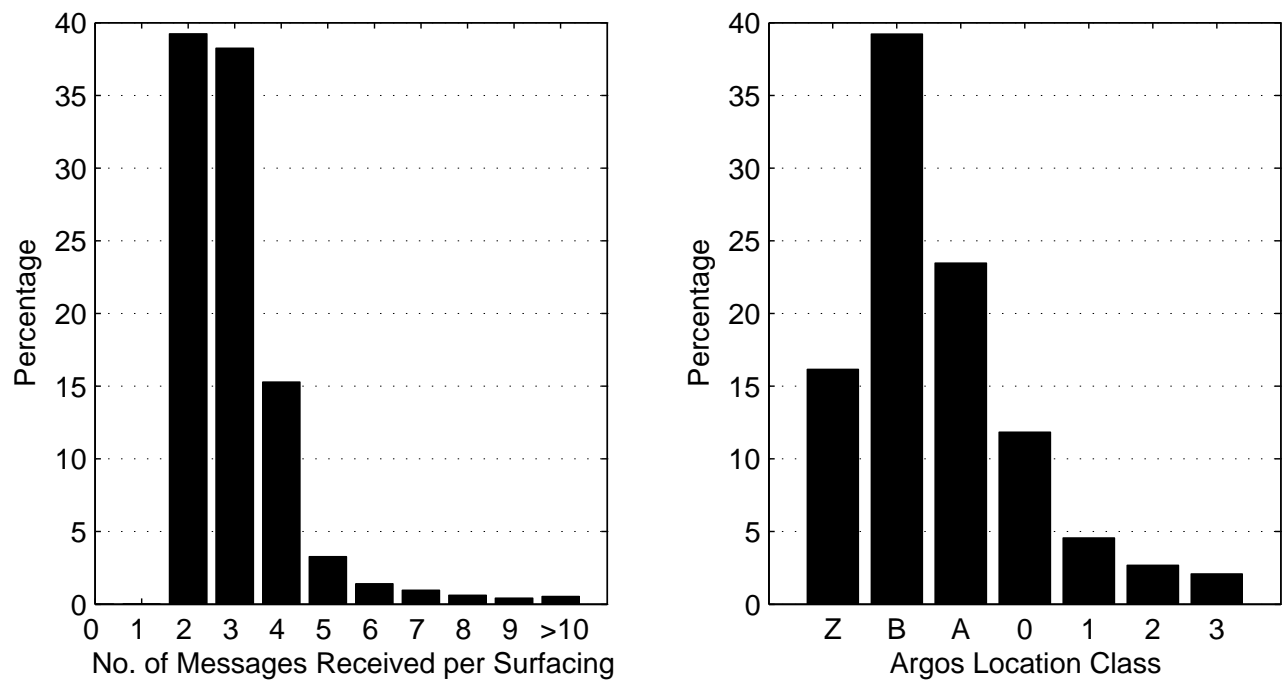

Fig. 4. Percentage of Argos messages received for each surfacing (left) and the Argos location class for each calculated position (right). The position accuracy is: $3(<250 \mathrm{~m}), 2(<500 \mathrm{~m}), 1(<1500 \mathrm{~m}), 0(>1500 \mathrm{~m})$, A (three messages received), B (two messages received), Z (no position fix). Data are from CTD-SRDLs south of $40^{\circ} \mathrm{S}$.

\section{Energy budget}

All energy required by a CTD-SRDL is delivered by a primary $3.6 \mathrm{~V} \mathrm{Li}-\mathrm{SOCl}_{2}$ cell, which drives the main processor, the Argos transmitter and the CTD sensors. We define three different states of the CTD-SRDL consumption wise: transmitting, full CTD sampling and only pressure sampling. The CTD-SRDLs are scheduled to broadcast about $50000 \mathrm{Ar}$ gos messages over their 300 day lifetime. Every transmission needs $1800 \mathrm{~mJ}$ and lasts for one second, totalling $6.9 \mathrm{Ah}$ over the deployment. Four times a day, a full CTD profile is recorded. During such profile the processor reads all sensors every second, which takes about $47 \mathrm{~ms}$ and requires $141.1 \mathrm{~mJ}$ for every minute, while the CTD package draws $928.8 \mathrm{~mJ}$ for every minute. Each profile/ascent is estimated to last for $1000 \mathrm{~s}$ on average, yielding $1.7 \mathrm{Ah}$ during the deployment.

Most of the time (about 1373 min a day) the CTD-SRDL is in the pressure only state. The main processor wakes up every $4 \mathrm{~s}$ for $47 \mathrm{~ms}$ to collect a pressure reading and process the results. Based on these results, the processor decides if the CTD-SRDL is at the surface and a transmission should be performed, if the CTD-SRDL is descending and a dive profile ( $\mathrm{P}$ only) should be recorded or if the CTD-SRDL is ascending and a full CTD profile should be recorded. In this state the processor and the pressure sensor draw $62.3 \mathrm{~mJ}$ for every min, which yields $2.0 \mathrm{Ah}$ over the lifetime. When the processor is asleep (about $98 \%$ of the time), the quiescent current is about $40 \mu \mathrm{A}$, which is in the same order as the selfdischarge rate of the battery at $45 \mu \mathrm{A}$. Together they account for 0.6 Ah during a CTD-SRDL deployment.
The total energy budget of a CTD-SRDL is therefore 11.2 Ah over its lifetime with an average current consumption of about $1.5 \mathrm{~mA}$. The battery capacity at this current and an assumed temperature of around $0^{\circ} \mathrm{C}$ is between 12 and $13 \mathrm{Ah}$, which gives a little reserve. However, this is not enough leeway to increase the number of profiles to 5 a day (an extra 1.7 Ah just for the extra transmissions). Nevertheless, the program can be modified for shorter deployments.

\section{Field experiences and real-time data}

CTD-SRDLs have been deployed on a variety of species for more than 5 years now, and have delivered very large quantities of behavioural and oceanographic data. For example, the international "Southern Elephantseals as Oceanographic Samplers" (SEaOS) project collected more than 22000 oceanographic profiles over 3 years in the Southern Ocean, and these represented a major addition to the World Ocean Database. Such datasets were usually received in near real-time during the deployment, with data analysed afterwards. Since recalibrations of the sensors are generally not possible, data quality has to be examined in an indirect way. Due to their similar nature to Argo float data, CTD-SRDL data are usually checked using methods similar to those used in the Argo community (Wong et al., 2003; Boehme and Send, 2005; Wong and Owens, 2009). Such post-deployment quality control adds uncertainty to the dataset, which is typically of order 0.005 in salinity, but can be higher (up to 0.1 ) in data sparse regions or regions of high variability in water mass properties (Wong et al., 2003; Boehme, 2004; Boehme and Send, 2005). However, bio-fouling does not 
seem to be a problem as the animals swim through the water column with about $1 \mathrm{~ms}^{-1}$ and spend most of the time at depths greater than $200 \mathrm{~m}$. Possible sensors drifts and postdeployment quality control are currently further investigated and will be part of a separate publication.

Boehme et al. (2008a) and Nicholls et al. (2008) found similar results for their datasets, with errors of $\pm 0.005^{\circ} \mathrm{C}$ in temperature and 0.02 in salinity, while Roquet et al. (2009) assumed an accuracy of $\pm 0.03{ }^{\circ} \mathrm{C}$ in temperature and 0.1 in salinity after post-deployment corrections. However, not all studies used the same version of the CTD sensor package and results can therefore differ. Generally, the salinity data collected during a CTD-SRDL deployment are too high when compared with ship-based measurements or climatology (Fig. 5). This may be caused by the aforementioned effect of the animal's head on the inductive field of the conductivity sensor (Fig. 1). In case of CTD-SRDLs deployed on southern elephant seals, with the instruments glued to the fur on the head close to the upper neck region, the derived salinities generally have offsets between -0.3 and 0 in salinity (Fig. 5). This needs further investigations to determine if this offset is due to the effect of the seal's head or has other causes. Nevertheless, such offsets can be reliably corrected using methods developed by the Argo community (Wong et al., 2003; Boehme and Send, 2005; Wong and Owens, 2009).

Since 2004 French collaborators in the SEaOS project deliver their CTD data to the French data center CORIOLIS in near real-time. However, since July 2008, a system has been operating to forward CTD-SRDL data to the Global Telecommunication System (GTS) in near-real time, from where it is distributed to data centres requiring rapid delivery data for numerical weather and ocean forecasting purposes. The "Marine Mammals Exploring the Oceans Pole to Pole ${ }^{4 "}$ (MEOP) project (involving 10 nations: Norway, UK, France, USA, Australia, Brazil, South Africa, Germany, Canada, Greenland) was the first to take the opportunity to provide CTD-SRDL data via the GTS, and produced up to $200 \mathrm{CTD}$ profiles daily north of $60^{\circ} \mathrm{N}$ and south of $40^{\circ} \mathrm{S}$ during the International Polar Year (since July 2008). To ensure the highest possible data quality, simple checks can be performed before data are placed on the GTS. Here, the most important part is the determination of the "head-effect" on the conductivity measurements and its correction in the realtime data stream. Usually, a time series of measurements is needed to be compared with climatology to calculate instrument specific corrections, but a general correction in the order of -0.1 could be employed from the start (Fig. 5).

\footnotetext{
${ }^{4}$ http://www.meop.info/en/index.html
}

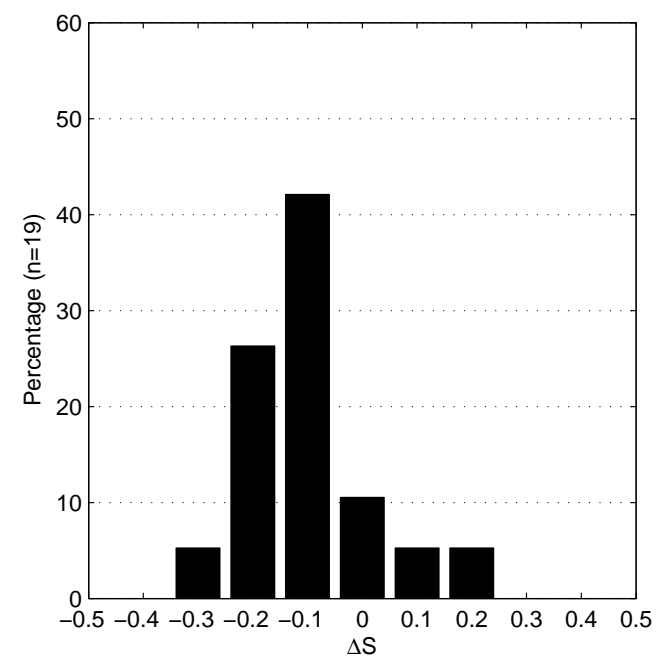

Fig. 5. Salinity differences between historical salinity data and CTD-SRDL data.

\section{Ethical issues}

Although some of the research involving CTD-SRDLs is motivated by an oceanographic need, the proposals have always been contingent on the belief by the marine mammal community that the study will further their aim to understand the importance of the oceanographic environment to the reproductive success and general well-being of marine mammals. Understanding the oceanographic context for a successful population brings a step closer the possibility of managing the oceans to ensure the animals' success.

\section{Summary and conclusions}

We have outlined an innovative approach to the collection of oceanographic data that has proven particularly useful in remote, previously inaccessible parts of the oceans. Accurate satellite positioning of diving marine animals, relatively high-accuracy sensors, and the potential to collect large numbers of profiles cost-effectively in near real-time make these studies particularly important in regions where traditional oceanographic measurements are scarce.

The uniqueness of the series 9000 CTD-SRDL lies in its data collection, processing and transmissions strategies, and we have demonstrated that such animal-borne sensors have the potential to provide very large quantities of oceanographic measurements of usable quality in near real-time, down to depths up to $2000 \mathrm{~m}$. The CTD-SRDLs record temperature with an accuracy of better than $0.005^{\circ} \mathrm{C}$, however, due to the limited availability of reference data for postprocessing, data are often associated with an error of $0.005-$ $0.01^{\circ} \mathrm{C}$. Salinity measurements are in general accurate to better than 0.02 , but have an associated offset of the order 
of 0.1 during the actual deployment due to the effect of the seal's head and body onto the inductive field. The salinity data therefore need post-processing for delayed-mode quality control, but a correction can be used to produce a realtime data correction to enhance the rapid delivery data.

Depending on the CTD-SRDL configuration, it is possible to sample and transmit hydrographic profiles on a daily basis. The CTD-SRDL is therefore intrinsically an eddy-resolving line-mode device, rather than a broad-scale one delivering quasi-randomly scattered data. The natural niche for CTDSRDLs in the observing system is in complementary measurements of boundary currents, ocean fronts and of property fluxes across lines (Boehme et al., 2008b), as well as coverage of undersampled ocean regions (Charrassin et al., 2008; Nicholls et al., 2008), e.g. high latitudes and coastal areas. They are thus a powerful complement to existing hydrographic sampling methods, and their utility will increase in the future as data quality improves further. Other enhancements will include different parameters that can be measured: a fluorometer is currently under development for incorporation into the existing CTD-SRDL package, and other sensors will be developed subsequently. Additional sensors would mean more data and new methods for relaying data from remote places and increasing the data transfer rate are investigated (e.g. 2-way Argos and Iridium), but energy constraints are still the all limiting factor. However, such developments will further enhance the contribution of the CTD-SRDL to the Global Ocean Observing System.

Acknowledgements. We would like to thank the Sea Mammal Research Unit Instrumentation Group for their endless work to improve their instruments. A special thanks to the staff and engineers of Valeport Ltd. for their help in designing the oceanographic sensors for the Sea Mammal Research Unit Instrumentation Group. The Naval Postgraduate School in Monterey, CA, USA, provided their calibration facilities for testing of CTD-SRDLs. We would also like to thank the three reviewers for their constructive criticism. Funding for instrument development was provided by the National Oceanographic Partnership Program Office of Naval Research. This research was funded by the Natural Environment Research Council (NERC) grants NE/E018289/1 and NER/D/S/2002/00426 and a NERC Co-operative Award in Science $\&$ Engineering PhD studentship supported by the Sea Mammal Research Unit Instrumentation Group of the University of St Andrews and the British Antarctic Survey.

Edited by: J. M. Huthnance

\section{References}

Aldrige, H. D. J. N. and Brigham, R. M.: Load carrying and maneuverability in an insectivorous bat: a test of the 5\% "rule" of radio-telemetry, J. Mammal., 69, 379-382, 1988.

Alverson, K.: The Global Ocean Observing System (GOOS), Hydro International, 12, 32-33, 2008a.

Alverson, K.: Filling the Gaps in GOOS, J. Ocean Technol., 3, 1923, 2008b.

Argos: Argos User's manual, Collecte Localisation Satellites (CLS), 1996.

Biuw, M., Boehme, L., Guinet, C., Hindell, M., Costa, D., Charrassin, J.-B., Roquet, F., Bailleul, F., Meredith, M., Thorpe, S., Tremblay, Y., McDonald, B., Park, Y.-H., Rintoul, S., Bindoff, N., Goebel, M., Crocker, D., Lovell, P., Nicholson, J., Monks, F., and Fedak, M. A.: Variations in behavior and condition of a Southern Ocean top predator in relation to in situ oceanographic conditions, P. Natl. Acad. Sci. USA, 104, 13705-13710, doi:10.1073/pnas.0701121104, 2007.

Boehlert, G. W., Costa, D., Crocker, D., Green, P., O’Brien, T., Levitus, S., and Le Boeuf, B.: Autonomous pinniped environmental samplers: Using instrumented animals as oceanographic data collectors, J. Atmos. Ocean. Tech., 18, 1882-1893, 2001.

Boehme, L.: Argo Quality Control in Highly Variable Enviroments, Argonautics, 5, 2-3, 2004.

Boehme, L. and Send, U.: Objective analyses of hydrographic data for referencing profiling float salinities in highly variable environments, Deep-Sea Res. Pt. II, 52, 651-664, doi:10.1016/j.dsr2.2004.12.014, 2005.

Boehme, L., Meredith, M., Thorpe, S., Biuw, M., and Fedak, M.: The ACC frontal system in the South Atlantic: monitoring using merged Argo and animal-borne sensor data, J. Geophys. Res., 113, C09012, doi:10.1029/2007JC004647, 2008a.

Boehme, L., Meredith, M., Thorpe, S., Biuw, M., and Fedak, M.: Monitoring Drake Passage with elephant seals: Frontal structures and snapshots of transport, Limnol. Oceanogr., 53, 2350-2360, 2008 b.

Boyd, J. D. and Linzell, R.: The Temperature and Depth Accuracy of Sippican T-5 XBTs, J. Atmos. Ocean. Tech., 10, 128-136, doi:10.1175/1520-0426, 1993.

Boyer, T., Levitus, S., Antonov, J., Locarnini, R., and Garcia, H.: Linear trends in salinity for the World Ocean, 1955-1998, Geophys. Res. Lett., 32, L01604, doi:10.1029/2004GL021791, 2005.

Charrassin, J.-B., Park, Y.-H., Le Maho, Y., and Bost, C.-A.: Fine resolution 3-D temperature fields off Kerguelen from instrumented penguins, Deep-Sea Res. Pt. I, 51, 2091-2103, doi:10.1016/j.dsr.2004.07.019, 2004

Charrassin, J.-B., Hindell, M., Rintoul, S. R., Roquet, F., Sokolov, S., Biuw, M., Costa, D., Boehme, L., Lovell, P., Coleman, R., Timmermann, R., Meijers, A., Meredith, M., Park, Y.-H., Bailleul, F., Goebel, M., Tremblay, Y., Bost, C.-A., McMahon, C. R., Field, I. C., Fedak, M. A., and Guinet, C.: Southern Ocean Frontal Structure and Sea-Ice Formation Rates Revealed by Elephant Seals, P. Natl. Acad. Sci. USA, 105, 11634-11639, doi:10.1073/pnas.0800790105, 2008.

Cochran, W. W.: Wildlife telemetry, in: Wildlife managment techniques manual, edited by: Schemnitz, S. D., Vol. Fourth Edn., Washington DC, The Wildl. Soc., 507-520, 1980. 
Costa, D. P., Klinck, J., Hofmann, E. E., Dinniman, M., and Burns, J. M.: Upper ocean variability in west Antarctic Peninsula continental shelf waters as measured using instrumented seals, DeepSea Res. Pt. II, 55, 323-337, doi:10.1016/j.dsr2.2007.11.003, 2008.

Curry, R., Dickson, R., and Yashayaev, I.: Ocean evidence of a change in the fresh water balance of the Atlantic over the past four decades, Nature, 426, 826-829, 2003.

Evans, W. E.: Uses of Advanced Space Technology and Upgrading the Future of Oceanography, AIAA Paper, 3, 7-01273, 1970.

Fedak, M.: Marine animals as platforms for oceanographic sampling: a "win/win" situation for biology and operational oceanography, Mem. Natl Inst. Polar Res., Spec. Issue, 58, 133147, 2004.

Fedak, M., Lovell, P., McConnell, B., and Hunter, C.: Overcoming the Constraints of Long Range Radio Telemetry from Animals: Getting More Useful Data from Smaller Packages, Integr. Comp. Biol., 42(1), 3-10, doi:10.1093/icb/42.1.3, 2002.

Fukasawa, M., Freeland, H., Perkin, R., Watanabe, T., Uchida, H., and Nishina, A.: Bottom water warming in the North Pacific Ocean, Nature, 427, 825-827, 2004.

Ganachaud, A. and Wunsch, C.: Improved estimates of global ocean circulation, heat transport and mixing from hydrographic data, Nature, 408, 453-457, 2000.

Gille, S. T.: Warming of the southern ocean since the 1950s, Science, 295, 1275-1277, 2002.

Globalstar: Data Communications, http://www.globalstar.com, last access: 1 December 2009.

Gould, J., Roemmich, D., Wijffels, S., Freeland, H., Ignaszewsky, M., Jianping, X., Pouliquen, S., Desaubies, Y., Send, U., Radhakrishan, K., Takeuchi, K., Kim, K., Danchenkov, M., Suttom, P., King, B., Owens, B., and Riser, S.: Argo Profiling Floats Bring New Era of In Situ Ocean Observations, EoS, 85, 179, 190-191, 2004.

Guinet, C., Dubroca, L., Lea, M., Goldsworthy, S., Cherel, Y., Duhamel, G., Bonadonna, F., and Donnay, J.-P.: Spatial distribution of foraging in female Antarctic fur seals Arctocephalus gazella in relation to oceanographic variables: a scale-dependent approach using geographic information systems, Mar. Ecol.Prog. Ser., 219, 251-264, 2001.

Hooker, S. K. and Boyd, I. L.: Salinity sensors on seals: use of marine predators to carry CTD data loggers, Deep-Sea Res. Pt. I, 50, 927-939, 2003.

Iridium: World Data Services, User Guide, Iridium Satellite LLC, 2003.

Lockheed Martin Sippican, Inc.: XBT: Expendable Bathythermograph, http://www.sippican.com, last access: 1 December 2009.

Lonergan, M., Fedak, M., and McConnell, B.: The effects of interpolation error and location quality on animal track reconstruction, Mar. Mammal Sci., 25, 275-282, doi:10.1111/j.17487692.2008.00264.x, 2009.

Lydersen, C., Nøst, O. A., Lovell, P., McConnell, B. J., Gammelsrød, T., Hunter, C., Fedak, M. A., and Kovacs, K. M.: Salinity and temperature structure of a freezing Arctic fjord monitored by white whales (Delphinapterus leucas), Geophys. Res. Lett., 29(23), 2119, 4 pp., doi:10.1029/2002GL015462, 2002.
Lydersen, C., Nøst, O. A., Kovacs, K. M., and Fedak, M. A.: Temperature data from Norwegian and Russian waters of the northern Barents Sea collected by free-living ringed seals, J. Marine Syst., 46(1-4), 99-108, doi:10.1016/j.jmarsys.2003.11.019, 2004.

McClain, E. P., Pichel, W. G., and Walton, C.: Comparative performance of AVHRR based multi-channel sea surface temperatures, J. Geophys. Res., 90, 11587-11601, 1985.

Mcconnell, B. J., Chambers, C., and Fedak, M. A.: Foraging ecology of southern elephant seals in relation to the bathymetry and productivity of the Southern ocean, Antarct. Sci., 4, 393-398, 1992.

McMahon, C. R., Field, I. C., Bradshaw, C. J., White, G. C., and Hindell, M. A.: Tracking and data-logging devices attached to elephant seals do not affect individual mass gain or survival, J. Exp. Mar. Biol. Ecol., 360, 71-77, doi:10.1016/j.jembe.2008.03.012, 2008.

Meredith, M. P., Naveira Garabato, A., Gordon, A., and Johnson, G.: Evolution of the Deep and Bottom Waters of the Scotia Sea, Southern Ocean, during 1995-2005, J. Climate, 21(13), 33273343, doi:10.1175/2007JCLI2238.1, 2008.

Meredith, M. P., Renfrew, I. A., Boehme, L., Biuw, M., and Fedak, M. A.: Seasonal evolution of the upper-ocean adjacent to the South Orkney Islands, Southern Ocean GLOBEC Special Issue: results from a "lazy biological mooring", Deep-Sea Res. Pt. II, accepted, 2009.

Nicholls, K. W., Boehme, L., Biuw, M., and Fedak, M. A.: Wintertime ocean conditions over the southern Weddell Sea continental shelf, Antarctica, Geophys. Res. Lett., 35, L21605, doi:10.1029/2008GL035742, 2008.

Quadfasel, D.: The Atlantic heat conveyor slows, Nature, 438, 565566, doi:10.1038/438565a, 2005.

Reynolds, R. W., Zhang, H.-M., Smith, T. M., Gentemann, C. L., and Wentz, F.: Impacts of in situ and additonal satellite data on the accuracy of a sea-surface temperature analysis for climate, Int. J. Climatol., 25, 857-864, doi:10.1002/joc.1168, 2005.

Roemmich, D., Riser, S., Davis, R., and Desaubis, Y.: Autonomous Profiling Floats: Workhorse for Broad-scale Ocean Observations, Mar. Technol. Soc. J., 38, 31-39, 2004.

Roquet, F., Park, Y. H., Guinet, C., Bailleul, F., and Charrassin, J.: Observations of the Fawn Trough Current over the Kerguelen Plateau from instrumented elephant seals, J. Marine Syst., 78(3), 377-393, doi:10.1016/j.jmarsys.2008.11.017, 2009.

Vincent, C., McConnell, B., Ridoux, V., and Fedak, M.: Assessment of Argos location accuracy from satellite tags deployed on captive gray seals, Mar. Mammal Sci., 18, 156-166, 2002.

Wong, A. P. S. and Owens, W. B.: An improved calibration method for the drift of the conductivity sensor on autonomous CTD profiling floats by $\Theta-S$ climatology, Deep-Sea Res. Pt. I, 56, 450 457, doi:10.1016/j.dsr.2008.09.008, 2009.

Wong, A. P. S., Johnson, G. C., and Owens, W. B.: Delayed-Mode Calibration of Autonomous CTD Profiling Float Salinity Data by

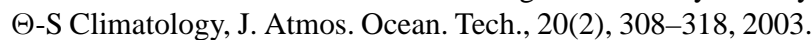

Zenk, W., Morozov, E., Sokov, A., and Müller, T. J.: Vema Channel: Antarctic bottom water temperatures continue to rise, CLIVAR Exchanges, 8, 24-26, 2003. 